\title{
HVMANITAS
}

\section{Espectáculo y teatralidad en Bacantes de Eurípides}

Autor(es): Tobías Nápoli, Juan

Publicado por: Faculdade de Letras da Universidade de Coimbra, Instituto de Estudos
Clássicos

URL

persistente:

DOI: $\quad$ DOI:http://dx.doi.org/10.14195/2183-1718_62_6

Accessed : $\quad$ 26-Apr-2023 09:42:04

A navegação consulta e descarregamento dos títulos inseridos nas Bibliotecas Digitais UC Digitalis, UC Pombalina e UC Impactum, pressupõem a aceitação plena e sem reservas dos Termos e Condições de Uso destas Bibliotecas Digitais, disponíveis em https://digitalis.uc.pt/pt-pt/termos.

Conforme exposto nos referidos Termos e Condições de Uso, o descarregamento de títulos de acesso restrito requer uma licença válida de autorização devendo o utilizador aceder ao(s) documento(s) a partir de um endereço de IP da instituição detentora da supramencionada licença.

Ao utilizador é apenas permitido o descarregamento para uso pessoal, pelo que o emprego do(s) título(s) descarregado(s) para outro fim, designadamente comercial, carece de autorização do respetivo autor ou editor da obra.

Na medida em que todas as obras da UC Digitalis se encontram protegidas pelo Código do Direito de Autor e Direitos Conexos e demais legislação aplicável, toda a cópia, parcial ou total, deste documento, nos casos em que é legalmente admitida, deverá conter ou fazer-se acompanhar por este aviso. 
humanitas

Vol. LXII

2010 


\title{
ESPECTÁCULO Y TEATRALIDAD EN BACANTES DE EURÍPIDES
}

\author{
JUAN TOBÍAS NÁPOLI \\ Centro de Estudios Helénicos \\ Universidad Nacional de La Plata
}

\section{Resumen}

Bacantes de Eurípides se convierte en una reflexión metadiscursiva sobre el concepto del género y sobre el carácter espectacular de la representación. De tal manera, creemos que la obra constituye una oportunidad única para analizar el modo en que los poetas contemplaron el fenómeno del género trágico en su carácter de representación. Intentaremos demostrar que, en los últimos años de su carrera teatral, el poeta se habría planteado una reflexión acerca del fenómeno del teatro: para ello se analizarán los valores de los distintos espacios en los que se desarrolla la trama de cada una de las acciones dramáticas y la inagotable cantera de procedimientos autorreferenciales: la presencia de una obra dentro de otra obra, la reflexión sobre las emociones que el teatro debe producir sobre los espectadores, los casos en los que un personaje se refiere a sí mismo o a los demás como a un actor y a sus acciones como a representaciones teatrales, y la referencia a la condición teatral de la escena.

Palabras clave: Eurípides, tragedia, Bacantes, teatralidad.

\begin{abstract}
Euripides' Bacchae becomes a metadiscoursive reflection on the concept of the genre and the spectacular nature of the performance. Thus, we believe that the work is a unique opportunity to analyze how the poets beheld the phenomenon of the tragic genre in its character of representation. Our claim is that, in the last years of his theatrical career, the poet would have proposed a reflection on the theatrical phenomenon. In order to support this claim, we will analyze the values of all the different spaces in which the plot of each one of the dramatic actions is developed and the inexhaustible source of self-referential procedures on the theater:
\end{abstract}


the presence of a play within a play, the reflection on the emotions that the theater must produce on the spectators, the cases in which a character refers to himself or others as an actor and to his actions as theatrical performances, and reference to the theatrical condition of the scene.

Key-words: Euripides, Tragedy, Bacchae, theatricality.

Bacantes de Eurípides, junto con Ifigenia en Áulide del mismo autor -así como con Edipo en Colono de Sófocles-, constituye una de las tres obras representadas en el año 406 a. C., el último del que tenemos textos completos de los autores de la tragedia clásica. Bacantes, por su parte, es una tragedia que, según la conocida definición de Aristóteles, se configura como una "imitación de una acción excelente y completa,... actuando los personajes y no a través de una narración, y que mediante compasión y temor lleva a cabo la expurgación de tales afecciones". ${ }^{1}$ Sobre la conformación genérica y el carácter mimético aristotélico de Bacantes no se han manifestado objeciones -como ocurre con otras obras del trágico- ${ }^{2}$ y no habría mucho para agregar. Sin embargo, el carácter representacional o espectacular de

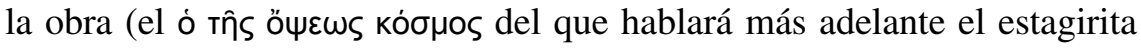
-1449b33) ofrece todavía varios detalles para el análisis.

Por otra parte, la conocida vinculación del género trágico con el culto de Dioniso, y el hecho de que la obra sea la única -entre las conservadasque trata de manera clara con el culto del dios patrono del género, ha permitido que muchos investigadores se acercaran al texto como un medio para profundizar el conocimiento del mito y del rito que está en el origen del género. ${ }^{3}$

Sin embargo, la riqueza del texto no se agota en estas perspectivas. La tragedia se convierte también -y es ello lo que queremos analizar- en una reflexión metadiscursiva del propio poeta: no sólo sobre la historia del género, sino principalmente sobre el mismo concepto de género trágico y sobre el carácter espectacular de la representación. De tal manera, creemos

1 Cf. Arist. Po. 1449b24-28. Las citas están tomadas de la edición de Lucas (1968). Las traducciones son siempre nuestras.

2 Cf., por ejemplo, Seek (1985).

3 Sólo a título ilustrativo, señalaremos (entre una amplia bibliografía) los tres textos de Pickard Cambridge (1946) (1962) y (1989). Una aproximación más moderna puede verse en Dabdab Trabulsi (1990); Easterling (1993); Easterling (1997); Foley (1980) y Friedrich (1996). Tal vez el texto más apropiado sea Segal (1982). 
que la obra constituye una oportunidad única para analizar el modo en que los propios poetas contemplaron el fenómeno del género trágico en su carácter de representación, en el mismo tiempo en que el género se dirigía hacia su desaparición.

M. F. Silva ha llamado la atención sobre uno de los temas más actuales dentro de la crítica euripidea: el de su doble condición de dramaturgo, por un lado, y de observador y especulador acerca del fenómeno teatral, por el otro. ${ }^{4}$ En este sentido, las obras definidas como novelescas serían las más apropiadas para buscar en ellas con mayor claridad rastros de esta actividad de crítica literaria, entre ellas Ifigenia en Táuride y Helena. M. F. Silva analiza especialmente Helena, a la que considera la pieza más expresiva de esta actitud de Eurípides como crítico teatral. En ella, la protagonista no sólo emite opiniones sobre las estrategias teatrales implementadas, sino que también, como proyección del poeta dentro de la ficción dramática, se atreve a montar una representación para eludir al enemigo (la escena de la mechánema), constituyendo así un testimonio del tópico del teatro dentro del teatro. Sin embargo, se ha señalado de manera adecuada que esta muerte fingida de Menelao, propuesta por Helena como estrategia de escape, constituye en realidad una maquinación semejante a la que ya se encontraba en Electra de Sófocles. ${ }^{5}$ En Electra (obra que, además, puede datarse en el año 413 a. C., mientras que Helena es sin dudas del 412, un año más tarde $)^{6}$ se produce un engaño muy similar, cuando, ante la presunta urna que contendría las cenizas de su hermano Orestes, Electra escucha del pedagogo y del propio Orestes las noticias de su muerte, que ellos han fraguado. Resulta verosímil pensar que Eurípides ha explotado el recurso hasta un punto extremo.

La diferencia en la consideración de la teatralidad entre ambas obras resultará significativa, y nos permitirá comprender la preocupación euripidea por los problemas de reflexión metateatral: en Electra, el recurso del ठó̀os es urdido por Orestes y el pedagogo, pero la escena del llanto de Electra es sincera, ya que la joven, en su ignorancia, cree realmente en la muerte de su hermano. En Helena, en cambio, el engaño es llevado a un punto extremo, ya que toda la escena del trénos de Helena se presenta como parte de un dólos fingido: ella misma fue la que urdió el dólos del que ahora es

\footnotetext{
4 Cf. Sousa e Silva 2005: 243-267.

5 Cf. Zielinski 1927: 54-58 y Ghali-Kahil (1955).

6 Cf. sobre la cuestión Matthiessen (1964).
} 
testigo y actora. Vemos allí un actor actuando de Helena, quien, al mismo tiempo que, como autor teatral, diseña una representación que le permite escapar de Teoclimeno, actúa a su vez la situación ficticia, representando el papel de una viuda reciente y sorprendida. Sin embargo, hay otra diferencia sustancial en las tramas de ambos engaños: mientras en Sófocles ha sido Apolo quien dio la orden de llevar a cabo la venganza por la muerte de Agamenón a través del engaño que constituye la estructura argumental de la tragedia, aquí no ha sido la divinidad quien urdió la mechánema, sino exclusivamente los hombres (convertidos, de este modo, en autores de ficción). Además, la orden de Apolo, en Sófocles, intentaba restaurar el desorden cósmico producido por el asesinato perpetrado por Clitemnestra; mientras que, en Eurípides, es la mera salvación individual de los esposos lo que se resuelve a través de este engaño.

Por otra parte, el modo en que Helena urde la trama del engaño deja clara la noción de que la apariencia puede no corresponderse con la realidad y de que sólo es una mímesis de ella. Su actuación, en cambio, exhibe ante el público y los restantes personajes las habilidades propias de un actor teatral. Estas reflexiones ponen en primer plano una discusión acerca del problema de la teatralidad. Es por ello que ahora nos interesará analizar los problemas vinculados con la teatralidad en Bacantes, donde, según creemos, la reflexión metateatral alcanzará su punto máximo. Algunas observaciones iniciales sobre el concepto nos permitirán precisar nuestra intención.

En la vida cotidiana, el término teatralidad es utilizado con frecuencia para aludir a un comportamiento similar al de quien se presenta sobre un escenario. El adjetivo teatral y, por tanto, el sustantivo teatralidad, se utilizan para aludir a la circunstancia de que los participantes de los hechos comentados adquieren la categoría de actores y actrices, en cuanto actúan y no se comportan naturalmente, sino que asumen conductas de personajes ficticios -otros que ellos mismos-, sobre la base de la presunción de la existencia de unos espectadores. En cambio, en el campo literario la denotación más corriente -a partir del formalismo ruso y el estructuralismo- ha consistido en referirse con el término teatralidad a la esencia o a la especificidad del teatro, a la cosidad de la cosa de la que hablaba Heidegger. En algunas ocasiones, el concepto se refiere a la esencia del texto dramático; en otras, a las cuestiones vinculadas con la puesta en escena. ${ }^{7}$ Roland Barthes, al examinar la definición de teatralidad, señala que "It is theater-minus-text, it

7 Cf. Féral (1985). 
is a density of signs and sensations built up on stage starting from the written argument; it is that ecumenical perception of sensuous artifice - gesture, tone, distance, substance, light - which submerges the text beneath the profusion of the external language". ${ }^{8}$

Sin embargo, esta definición de la teatralidad como theater-minus-text deja fuera muchos aspectos importantes de la esencia del teatro, y no nos servirá para definir la teatralidad de Bacantes. Más apropiada nos resultará la explicación de Elizabeth Burns, para quien es solamente la presencia de un espectador consciente de ser espectador lo que transforma una situación en teatral. ${ }^{9}$ Esta definición (válida incluso para una realidad más compleja que el propio teatro) nos resultará apropiada por varias razones. Habrá en la teatralidad dos rasgos distintivos: a) la presencia de un sujeto que mira y de un objeto mirado, y b) la presencia de un objeto -lo mirado-, que es concebido como ficción por parte del sujeto mirante -el espectador. En el fondo, no sólo se requiere el sujeto espectador, sino principalmente que este sujeto entienda que el objeto mirado es una ficción, una representación. ${ }^{10}$ Así entiende la representación el público del teatro, y en esta mirada radica su valoración de la teatralidad.

Sin embargo, cuando, en una representación teatral, un personaje del ámbito de la ficción representada observa un objeto con conciencia de su carácter ficticio o representacional, estamos entonces en presencia del fenómeno del teatro dentro del teatro, o de una teatralidad de segundo grado, que no radica simplemente en la mirada de los espectadores sino en la del personaje como espectador del objeto representado. Es el punto de partida de Bacantes.

En este sentido, debe decirse que Bacantes constituye una inagotable cantera de procedimientos autorreferenciales sobre el teatro: la presencia de una obra dentro de otra obra, la reflexión sobre las emociones que el teatro debe producir sobre los espectadores, los casos en los que un personaje se refiere a sí mismo o a los demás como a un actor y a sus acciones como a representaciones teatrales, y la referencia a la condición teatral de la escena -y al histrionismo de los personajes- en las intervenciones que suplen las acotaciones escénicas. Analizaremos entonces estos aspectos del texto.

\footnotetext{
8 Cf. Barthes 1994: 75.

9 Cf. Burns (1972).

10 Cf. Villegas 1996: 7-15. En la misma dirección, cf. Goutman 1992: 130-138.
} 


\section{a. Teatro dentro del teatro}

En el prólogo de Bacantes, un actor que representa al dios Dioniso, patrono de la representación teatral, sube al theologeion para expresar desde allí sus intenciones: el dios va a revestirse con la ropa de un mortal, para convertirse en profeta de su propio culto y castigar la impiedad del rey de Tebas, el joven Penteo, que, con argumentos de política racionalista, quiere oponerse a las prácticas de las mujeres que han llegado desde el Asia para difundir las prácticas de su nuevo culto. ${ }^{11}$ El éxodo de la tragedia vuelve a mostrarnos al dios en su epifanía, extrayendo las conclusiones acerca de lo que acaba de ocurrir sobre la escena en el cuerpo de la tragedia. De manera que la estructura episódica de la tragedia muestra a un actor que representa el papel de Dioniso quien, a su vez, se ha vuelto a disfrazar para representar el papel de otro personaje, el profeta de su propio culto. En términos amplios, se trata de una representación dentro de otra representación, o de una teatralidad de segundo grado.

En la mirada de los espectadores, la obra entera representa un momento del mito heroico que aparece ante sus ojos como la imitación de una acción: en este sentido, como una ficción. A los ojos del personaje de Dioniso, todo lo que ocurre sobre la ciudad de Tebas en la parte episódica responde a un plan que él ha urdido, y está destinado a dejar una enseñanza a personajes y espectadores.

Esta representación, por supuesto, no tendrá las mismas características que adquiere el tópico del teatro dentro del teatro en la escena barroca e isabelina en adelante. ${ }^{12}$ Sin embargo, debe señalarse que esta aparición del tópico no puede menos que corresponderse con la importancia que los atenienses le adjudicaron al teatro en la vida cotidiana y con una concepción generalizada del mundo y de la vida como teatro. El tópico del Theatrum mundi tiene una tradición más extensa de lo que muchas veces se piensa. ${ }^{13}$ En el Filebo, ya Platón decía que "en las lamentaciones y tragedias, no sólo del teatro, sino en la tragedia y comedia de la vida humana, el placer va mezclado con el dolor". Muestra de esta manera que la concepción del mundo y de la vida como teatro no es una novedad barroca, sino que presenta una larga trayectoria desde el mundo clásico. E. Curtius encontraba

11 Cf. Vernant 1985: 31-58.

12 Cf. Orozco (1969) y Hernandez Valcarcel (1988-1989).

13 Se discute si el tópico nació con el teatro isabelino de Shakespeare o en el barroco español, con Cervantes, Lope, Tirso y Calderón. Cf., sobre la primera posición, Gurr 1992: 123-31 y 142-6 y Ann Jennalie Cook 1981: 176-7. La segunda postura la sostienen AndresSuarez (1997) y Montes Huidobro 1982: 289-310. 
la misma metáfora de la vida como teatro a partir de Horacio y Séneca, pero no en otras citas de la Grecia clásica. ${ }^{14}$

Sin embargo, en Bacantes tenemos ya con claridad el tópico del teatro dentro del teatro. Como hemos señalado, habrá algunas diferencias con la constitución barroca e isabelina del tópico: la estructura episódica de la tragedia constituye una escenificación de la que sólo el dios y el público tienen conciencia. El rey de Tebas, Penteo, así como los dos grupos de ménades -las tebanas que se mueven en el espacio extra-escénico del monte Citerón y las asiáticas que conforman el coro-, tanto como el adivino Tiresias y el viejo rey Cadmo, desconocen que están formando parte de una representación teatral enmarcada. Sin embargo, el destinatario del aprendizaje que esta representación enmarcada comporta no es (como el rey Claudio en el Hamlet de Shakespeare) un personaje dispuesto a contemplar esa representación-que se efectúa sobre el mismo escenario teatral- y consciente del carácter ficticio de lo representado. Los personajes humanos son a un tiempo personajes de la representación primaria -en tanto constituyen actores que representan el papel que el autor teatral les ha asignado- y personajes de la representación secundaria -en tanto que, convertidos en figuras que actúan las acciones diseñadas por el dios ostensible y comandadas por el dios convertido en profeta de su culto, se convierten en objeto del aprendizaje propuesto por el dios como sentido de su presencia en Tebas. Por ello, sólo cuando caiga el telón de la representación enmarcada, los personajes de la representación secundaria se convertirán en espectadores repentinamente concientes del drama que han protagonizado; podrán recién entonces, al tomar conciencia de la representación de la que formaron parte, extraer sus conclusiones o realizar el aprendizaje que la acción más profunda les ha planteado.

El carácter teatral de la estrategia del dios queda explícito desde el prólogo. También resulta explícita la intención de su estrategia. En el verso 4 dirá algo que tiene que ver con su transformación, con el cambio de forma (de dios a mortal) pero también con el cambio de función (de actor que personifica una obra de Eurípides a director que, convertido en actor, personifica su propia creación):

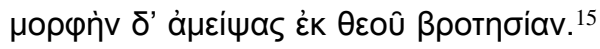

14 Cf. Curtius 1976: 203-208.

15 Después de cambiar la forma de un dios por la propia de un mortal... Las citas están tomadas de la edición de Dodds (1960) y han sido confrontadas con la última edición de Seaford (1996). Las traducciones son siempre nuestras. 
Repitiendo de manera anular la misma idea, cerrará su rhésis en 53-54:

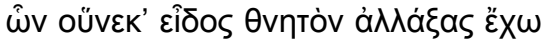

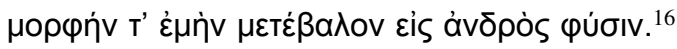

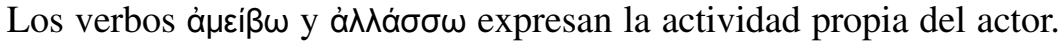
Sin embargo, creemos que hay una deliberada profundización, entre el valor más general del primero (que significa cambiar, intercambiar) y el más específico del segundo: el diccionario de Liddle \& Scott da para el verbo à $\lambda \lambda$ á $\sigma \omega \omega$ el valor específico de la actividad del actor teatral: make other than it is. Esta acción del dios que adopta el carácter de un actor, que se ha hecho otro de lo que es adoptando la forma mortal, tiene una finalidad

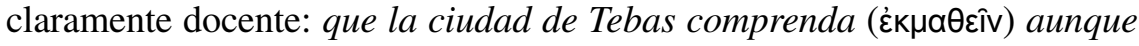
no quiera. Así lo dirá en 39-42:

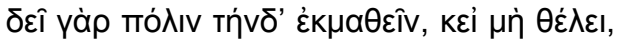

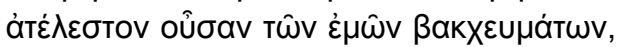

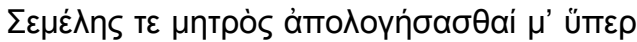

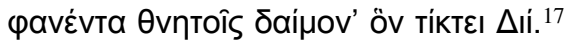

La finalidad de la tragedia termina por cumplirse: también se cerrará el circuito del aprendizaje de manera anular, cuando Agave exprese (1296) que estas intenciones del dios han sido dolorosamente exitosas:

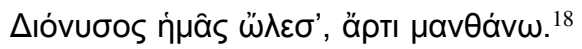

La vuelta a la salud y a la razón ha terminado con la ficción de la representación enmarcada. Sin embargo, la práctica del teatro enmarcado no termina con esta estructura: numerosas representaciones de tercer grado se producen en el marco de la representación de segundo grado. No obstante, el público nunca contempla esta representación de tercer grado, sino que se entera de ella por el relato de un testigo-espectador que forma parte de

16 Por todo esto tengo, después de hacerla distinta de la mía, una apariencia mortal, y adopté mi forma de ahora a partir de la naturaleza de un varón.

17 Pues es necesario que esta ciudad comprenda (aunque no quiera) que no está iniciada en mis ceremonias báquicas, y que yo defienda a mi madre Semele, mostrándome ante los hombres como el dios que ella engendró con Zeus.

18 Dioniso nos destruyó: recién ahora comprendo. 
la representación de segundo grado. Así, por ejemplo, un mensajero que forma parte de la obra montada por Dioniso nos contará el modo en que las mujeres de Tebas desarrollan un ritual de calma y sosiego, o de furia y violencia cuando son interrumpidas en sus prácticas. Otro mensajero nos contará también el modo en que Penteo, como personaje de esta obra representada, contempló una nueva obra, representada exclusivamente para él por las ménades tebanas sobre las laderas del monte Citerón, y lo convirtieron de manera violenta de testigo en protagonista de la práctica cultual. Para testimoniar este carácter teatral de lo representado, el dios travestido en profeta de su culto hará que el rey de Tebas también se travista en bacante para contemplar el espectáculo que le tiene reservado. La representación teatral se profundiza en niveles de creciente complejidad.

\section{b. Las emociones sobre los espectadores}

En el verso 815 de Bacantes, Dioniso, el dios que está sobre el escenario como profeta de su propio culto, trata de persuadir a Penteo para que vaya a observar algunos aspectos del culto dionisíaco de las ménades tebanas sobre el monte Citerón. Al hacerlo, el dios pone a los espectadores de la tragedia como testigos de la existencia, en Penteo, de un sentimiento que sirve de espejo del sentimiento que los propios espectadores deben experimentar al contemplar una representación teatral. Ese sentimiento se ha denominado la paradoja trágica, ${ }^{19}$ y consiste justamente en el hecho de que el espectador de la tragedia encuentre placer en la contemplación del sufrimiento. ${ }^{20}$ En este caso, será Penteo, el espectador del drama humano que las ménades representarán sobre el monte Citerón, ${ }^{21}$ quien encuentre placer ante este espectáculo. Los sentimientos que manifieste Penteo ante la contemplación de esta representación espejarán, de alguna manera, los sentimientos que se esperan en los auténticos espectadores de la representación teatral completa.

Desde la perspectiva escénica, nos resulta pertinente establecer una clara distinción entre los dos diferentes escenarios dentro de los que se desarrolla la tragedia: habrá, entonces, un escenario teatral aludido o referenciado (constituido por el espacio distante del monte Citerón, que se convierte, de este modo, en escenario de representación de una obra teatral

19 Cf. Segal 1991: 244-253.

20 Cf. Segal (1993).

21 Sobre el significado del menadismo, cf. De Bouvrie 1997: 75-114. 
de la que primero un mensajero y luego Penteo serán testigos oculares), que se manifiesta como tal en el curso de una narración en el interior del otro escenario, que podemos denominar el escenario teatral real u ostensible, ya que es visible a todos los espectadores atenienses. Son los espectadores quienes, a su vez, deberán hacer la adecuada reconstrucción de la manera en que Penteo pasa de un escenario al otro, y se convierte de personaje escénico de una tragedia en espectador de otra, aunque luego termine como actor secundario de otra representación (esta representación no será ahora sólo escénica, sino también cultual) a la que él mismo le negaba validez.

Veamos las cosas con un poco de detenimiento. En el clímax del tercer episodio, el dios travestido en profeta de su propio culto (es decir: un actor que representa el papel de un dios que actúa como un actor, puesto que, al tiempo que el actor representa el papel del dios, este dios representa el papel de un personaje de tragedia -el profeta-, que actúa como alguien que no es, propiamente, él mismo) le pregunta a Penteo:

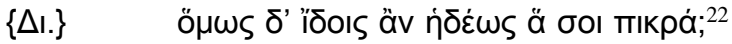

A través de la unión de una sinestesia con un oxímoron, donde se conjugan sensaciones visuales (verías) y gustativas contrastadas (agradablemente-lo amargo), se nos presenta de manera abrupta el problema de la paradoja trágica: para el dios travestido en profeta, Penteo verá con agrado lo que es, en realidad, amargo. La pregunta, evidentemente, nos pone en presencia de la cuestión de las emociones de los espectadores de la tragedia. La interrogación acerca del tipo de participación que el espectador obtiene de la representación dramática, encarnada aquí por Penteo y su conflictiva contemplación del culto dionisiaco, está en el centro del interés de la tragedia, que refleja de esta manera la reacción que los propios espectadores del drama entero (es decir, de las dos representaciones en los dos escenarios) obtendrán ante la contemplación de la muerte de Penteo. Intentaremos señalar las diferentes maneras en que esta relación entre el espectador y el espectáculo contemplado (en los distintos espacios escénicos en que esta relación ocurre) se representan en Bacantes y las emociones que esta contemplación suscita en el personaje que funciona además como espectador: creemos que la tragedia procura retratar la misma reacción que el hecho dramático en su conjunto debe suscitar en el verdadero espectador.

22 ¿Verías agradablemente lo que es amargo para ti? 
Un ejemplo de la épica puede aclarar un poco la perspectiva planteada. En Homero, hay dos escenas que, en el interior de la acción narrada, espejan, de un modo similar al que plantea Bacantes, el tipo de intimidad ideal que se produce entre el ejecutor de la performance épica con su propio público y los efectos que esta intimidad procura producir en el oyente: se trata del momento en que Aquiles, en el canto I de Ilíada (352-427), le narra a su madre, la diosa Tetis, lo que le ha ocurrido con Agamenón. En Odisea 23. 300-372, es Odiseo quien le hace a su recientemente recuperada esposa Penélope un resumen de sus aventuras. En cada caso, el oyente, comprometido emocionalmente con aquello que escucha, se conmueve hasta las lágrimas con el relato escuchado. La relación narrador-oyente, en el interior del propio relato épico, sirve de espejo de la esperada relación rapsoda-oyente en el marco de la ejecución del canto épico.

En Bacantes la cuestión se complica. Se produce una serie muy amplia de situaciones en las que se relacionan el espectador y el espectáculo contemplado, a las que podríamos clasificar, desde la perspectiva del espectador, y de manera simplificada, en dos posibilidades:

a) La contemplación de una performance épica: los espectadores de primer grado -sentados en las gradas- escuchan (como el público de la épica) el relato de un personaje ante otro personaje. Este personaje que escucha es, a su vez, oyente de segundo grado. Pero el relato del mensajero, a su vez, trata acerca de representaciones dramáticas que se produjeron fuera de la escena, ante un testigo diferente, que es, a su vez, espectador de tercer grado o aludido, ${ }^{23}$

b) La contemplación de una performance trágica: los espectadores de primer grado -sentados en las gradas- contemplan auténticas representaciones trágicas, las que, a su vez, forman el marco de una representación dramática en segundo grado (la cual se desarrolla ante la contemplación

23 El ejemplo paradigmático de estos relatos ante un espectador-personaje son los dos relatos de mensajero de los versos 677-774 y 1043-1153: en la representación teatral, el público contempla cómo un mensajero le relata a Penteo -el espectador en segundo grado- lo que ocurrió en el monte -aquello que constituye la acción dentro de la acciónante la contemplación de un espectador-personaje de tercer grado (los hombres que habían interrumpido las celebraciones cultuales de las ménades tebanas). Sobre los relatos de mensajero en Bacantes puede consultarse Buxton 1991: 39-48 y De Jong 1991: 120. Sobre la técnica narrativa en la representación teatral, cf. Goward (1999). 
de un personaje que es, al mismo tiempo, espectador de segundo grado y personaje de la representación de primer grado que le sirve de marco). ${ }^{24}$

Ambas situaciones permiten explorar el efecto que produce la contemplación de un espectáculo: a) por lo que el espectador real -de primer grado- ve que le pasa al personaje-espectador de segundo grado cuando escucha lo que le pasa al espectador del espectáculo narrado, o espectador de tercer grado; y b) por lo que el espectador real -de primer grado- ve acerca del modo en que reacciona el personaje-espectador (de segundo grado) ante la representación enmarcada. De esta manera, ambas situaciones sirven también de espejo respecto del efecto que debe producir la representación teatral sobre el espectador. Es evidente que, en los últimos años de su carrera teatral, el poeta se habría planteado una reflexión acerca del fenómeno del teatro. ${ }^{25}$

Por otra parte, la pregunta acerca del tipo de participación que el espectador obtiene de la representación dramática es ejemplificada aquí, especialmente, con Penteo, quien en las dos situaciones descriptas se comporta como personaje de primer grado y espectador de segundo grado, ya que contempla la ejecución y la progresión del culto dionisiaco, que se representa ante sus ojos como en una performance teatral enmarcada. Esta contemplación de Penteo del culto dionisíaco se presenta ante los ojos de los verdaderos espectadores a partir de distintos espacios teatrales:

a) El espacio escénico representa la ciudad de Tebas, la ciudad griega visitada por el profeta del nuevo culto, que proviene del Asia; pero junto con el palacio regio de Tebas (cuya puerta constituye el centro de la escenografía) se ve la tumba de Sémele y las ruinas de su casa, de manera que ya desde un principio este espacio cívico griego se presenta invadido ( $\mathrm{y}$, de alguna manera, modificado en su significación) por sus referencias respecto del ámbito sagrado del dionisismo. Cada uno de los cuatro ámbitos del espacio escénico (orchestra, logeion, teologeion y mechané) será destacado en esta

24 Ejemplos paradigmáticos de estas situaciones son, por ejemplo, todo el primer episodio (170-369), en que el espectador ve el modo en que reacciona Penteo ante la contemplación de Cadmo y Tiresias, quienes, a través de un travestimento, se han convertido en personajes de una representación cultual dionisíaca. Además, la tragedia toda conforma una representación enmarcada, en la medida en que todas las reacciones de Penteo se producen ante este Dioniso que está representando el papel de un profeta de su propio culto, es decir, que está desarrollando una acción dramática secundaria ante la contemplación de Penteo.

25 Cf., al respecto, Easterling 1991: 49-59. 
doble y creciente vinculación entre un espacio cívico en retirada y un espacio sagrado en participación creciente.

b) El espacio extra-escénico, por su parte, se divide en dos ámbitos bien diferenciados: el primero está constituido por los espacios interiores, como la prisión de Penteo desde la que escapa Dioniso; el segundo está constituido por los espacios exteriores, como el monte Citerón, habitado por las recién convertidas ménades tebanas, en donde se celebra el culto dionisiaco y que, en su referencia con la ciudad de Tebas representada en el espacio escénico, termina de definir las conocidas oposiciones o polaridades entre ciudad-campo, adentroafuera, propio-ajeno, masculino-femenino, diurno-nocturno, etc.

c) Finalmente, el espacio remoto estará constituido por los lugares desde donde viajan en peregrinación propagandística las ménades asiáticas que acompañan al profeta y que, a través de sus cantos corales, amplían la serie de oposiciones o polaridades que dan sentido a la tragedia, al incluir, además de las anteriores, la oposición entre griego-bárbaro y la que se produce entre un ciudadano incrédulo y un creyente devoto.

Las representaciones de los distintos momentos del culto y los distintos espacios en donde se producen cada uno de los hechos de la tragedia, así como su manera de ser contemplados: de manera abierta (ante todos los espectadores) o cerrada (exclusivamente ante Penteo o algún otro de los personajes) ofrecen una oportunidad para que los asistentes a la performance trágica contemplen a los personajes (principalmente a Penteo) en sus diferentes reacciones emotivas ante la visión de un espectáculo siempre cambiante y para que problematice sus propias referencias con el espectáculo contemplado.

Un análisis más detallado de algunos ejemplos nos permitirá apreciar mejor el modo en que Eurípides ha privilegiado la problemática teatral en la última de sus creaciones. Así, por ejemplo, en el comienzo del tercer episodio, un mensajero le cuenta a Penteo la manera en que ha visto a las ménades tebanas mientras cumplían sus ritos en la montaña (677-774), con la doble instancia de las bacantes en calma y las bacantes en frenesí por la intromisión de un extraño al culto. ${ }^{26} \mathrm{El}$ énfasis sobre el aspecto visual del

26 Sobre la vinculación de la furia destructiva de las ménades con la sexualidad femenina fuera de control puede consultarse Segal 1984: 195-212, Zeitlin 1982: 129-157 y Seidensticker 1979: 181-190. 
relato está subrayado de manera ostensible, tanto que el mensajero le cuenta a Penteo (y a los espectadores atenienses y a los de toda la posteridad) que se ve obligado a exclamar, ante la contemplación de las bacantes que se despiertan del sueño (692-694):

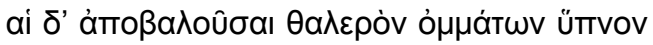

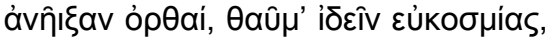

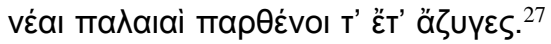

Debe notarse que el mensajero, en el momento de efectuar ante Penteo este relato, desempeña dos funciones teatrales distintas: a) es el relator de una acción de segundo grado ante un espectador-oyente; b) pero, al mismo tiempo, ha sido espectador de tercer grado del espectáculo de las ménades

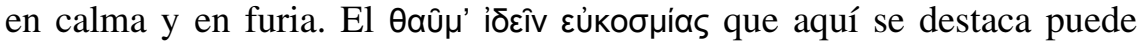
aparecer como tal en la medida en que anteriormente el mensajero ha sido espectador de lo que ahora narra. Al final de este relato, cuando la calma ha dejado paso a la furia destructiva de las ménades, el mismo mensajero se sorprenderá nuevamente del espectáculo que ha contemplado: aunque no es el espectáculo de las ménades ante los ojos de los varones que las contemplan lo que se convierte en un prodigio; el nuevo espectáculo estará constituido por los varones griegos que acompañan al mensajero y que intentaron apresar a las mujeres (759-760):

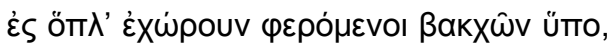

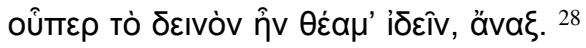

Es decir, la reacción de los espectadores de tercer grado ante el espectáculo se convierte, nuevamente, en un espectáculo diferente (¿deberíamos hablar de un espectáculo de cuarto grado?). El compromiso ante la contemplación por parte de este público que se convierte en personaje es uno de los efectos propios de la representación teatral.

El relato del segundo mensajero (1043-1153) narrará de manera simétrica el momento en que se ha contemplado, en el escenario teatral

27 Unas, arrojando el dulcísimo sueño de sus ojos, se levantaron, erguidas, prodigio de buen orden digno de ver: jóvenes, ancianas y vírgenes aún no uncidas.

28 Corrieron hacia las armas para llevarlas en contra de las bacantes. Y el espectáculo de estas cosas era algo pasmoso de ver, rey. 
aludido del monte Citerón, a las ménades en calma y su reacción cuando han descubierto la intromisión de Penteo. ${ }^{29}$ Sin embargo, habrá una clara diferencia entre las conductas del primer mensajero (que se convierte de espectador en personaje) y este Penteo (que se convertirá de espectador de segundo grado -en la medida en que había podido contemplar el modo en que el espectáculo de las ménades le fue descrito por el primer mensajero- en espectador de tercer grado -en la medida en que otro mensajero nos cuenta el modo en que contempla a las ménades en furia). En este último caso, cuando se ven poseídas por una furia sobrenatural, las ménades tebanas destruyen en rito báquico a aquel que transgredió las prohibiciones rituales y lo convierten de un espectador de tercer grado... en un elemento del decorado escénico: Penteo, muerto y desmembrado, pasa a formar parte de los elementos icónicos que representan la presencia del culto de las ménades sobre el escenario, como el tirso y la hiedra. La progresión de la tragedia hará que este elemento escénico de tercer grado (el público se entera de la manera en que Penteo se convirtió en un objeto del ritual báquico por el relato que el mensajero le hace al coro acerca del modo en que el mensajero lo vio sobre el monte) se convierta en un elemento escénico de la representación de primer grado, visible para los espectadores, cuando la propia Ágave ingrese sobre el espacio escénico con la cabeza de Penteo entre sus manos. La conclusión de Cadmo es muy clara: lo que ha ocurrido sobre el escenario aludido (y lo que ocurrirá en el escenario teatral real) es un espectáculo doloroso de ver (1244):

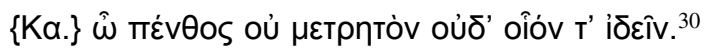

En ambos casos, los mensajeros han sido espectadores de una representación de dos caras: una plácida y dichosa y la otra espeluznante. Sin embargo, poco podemos decir acerca de sus emociones, ya que sólo nos enteramos de sus reacciones. Por ello, de lo que podemos ser testigos es solamente de las consecuencias de estas emociones: los convierten de espectadores en personajes. De todas maneras, ellos narran lo que han visto al modo en que el rapsoda de la épica narra lo que ha oído; pero el público del teatro no puede observar sus reacciones inmediatas ante la contemplación del espectáculo del que han sido testigos, ya que los hechos ocurren siempre

29 Cf. Barrett 1998: 337-60.

30 ¡Oh, dolor inconmensurable e imposible de ver! 
en un espacio alejado del espacio escénico y en un tiempo pasado. Para el espectador de la representación teatral, por lo tanto, su propia reacción se debe manifestar a partir de la confiabilidad respecto de las palabras de los mensajeros. Nuevamente, como en la épica, la verosimilitud de lo narrado depende de la confiabilidad del narrador, y ello presenta a la tragedia como un desafío a la interpretación del público.

Sin embargo, la narración de la relación espectador-espectáculo que traen sobre la escena estos mensajeros tiene una función de una importancia mayor: presenta ante los espectadores teatrales de primer grado, de una manera crecientemente problemática, una cuestión central, que constituye una reflexión sobre esta relación entre el espectáculo y el espectador.

Sobre el escenario del teatro hay, no obstante, un momento en el que el público mismo es espectador de las reacciones de uno de los personajes teatrales ante un espectáculo que contempla ante su propia vista (lo que hemos denominado "la contemplación de una performance trágica"): se trata del momento en que Penteo acecha, contempla y reacciona ante diversas circunstancias vinculadas con el culto dionisíaco que tiene ante sus ojos. Estas representaciones del culto tienen un objetivo bien definido por la propia divinidad en el prólogo (39-42).

La finalidad de la aparición de Dioniso y de todas las celebraciones cultuales que lo acompañan es didáctica: procuran enseñar a la ciudad y al rey que también ellos deben participar de estas celebraciones. Estas celebraciones se convierten, entonces, en espectáculos didácticamente preparados por el dios, y son presenciados por Penteo a la vista de los verdaderos espectadores. Entre estas celebraciones espectaculares presenciadas por el rey se encuentran, por ejemplo, la ejecución de un segmento del culto dionisíaco por parte de las ménades asiáticas sobre el escenario teatral, en el momento de celebrar el himno que constituye la párodos de la tragedia; la escena del primer episodio, en que su abuelo Cadmo y el profeta Tiresias se visten como bacantes para ir a celebrar el culto; los milagros del palacio que dejan libre al profeta que había apresado el rey bajo la acusación de haber sido responsable de traer este culto desconocido. ${ }^{31}$ Después de esta última situación, el espectáculo se muda, junto con Penteo travestido en bacante (es decir, asumiendo la función de un actor), al espacio extraescénico exterior, en el monte. Si los espectadores han podido escuchar el modo en que los mensajeros contaron lo que vieron, solamente en el caso

31 Cf. Fisher 1992: 179-188. 
de Penteo es posible que los propios espectadores puedan observar las reacciones del personaje ante la misma contemplación de un fenómeno que lo atormenta. En esta perspectiva, serán los espectadores de primer grado, sin la mediación de declarantes, los testigos de las reacciones del personaje ante la contemplación de lo que ocurre.

Hemos analizado brevemente la significación de los espacios extraescénicos en función de lo que denominamos la contemplación de una performance épica. Tanto el monte Citerón en el que se desarrolla el nuevo culto con las mujeres tebanas, cuanto el espacio remoto, es decir, las lejanas regiones del Asia desde donde vienen las ménades auténticas que acompañan al profeta, están también plenos de un significado vinculado con el culto dionisíaco. Pero ello no será todo. El espacio escénico, por su parte, aquel sobre el que se representan los dos primeros grados de la performance teatral, merece una atención especial. Creemos que Eurípides ha pretendido definir de manera completa los cuatro ámbitos del espacio escénico de Bacantes a partir de su relación con el mismo significado del espacio extra-escénico y remoto, es decir: con el dionisismo.

Así, no debe sorprender que el comienzo de la obra esté marcado por Dioniso cuando habla desde el $\theta \varepsilon \circ \lambda$ oyeîov, el techo desde donde hablan ordinariamente los dioses. ${ }^{32}$ Pero también al final de la tragedia veremos la aparición ex machina de la divinidad, que se presenta y pronuncia su profecía. En los dos momentos de la representación, estos espacios quedan definidos como espacios sagrados por la participación indiscutible del dios en su apariencia de tal. Las posturas críticas racionalistas han querido ver en esta apertura y cierre divinos de la tragedia una ironía del poeta, que mostraría en estas estructuras estereotipadas de la obra la versión del mito tal como la conoce la tradición, cuando en realidad, en el cuerpo mismo de la tragedia, la acción habría seguido un camino diferente. ${ }^{33}$

Sin embargo, si analizamos con detalle veremos que las cosas se presentan de manera diferente: este espacio del theologeion y de la mechané definen el primer grado de la representación teatral. Lo que ocurre en medio, en el cuerpo de la tragedia, es una representación teatral de segundo grado. En ambas representaciones, el espacio juega el mismo papel: el papel del espacio sagrado. Sin embargo, mientras en la representación marco este

32 Cf. sobre esta cuestión Said 1989: 107-136.

33 Es lo que opinan, sobre todo, Verrall (1885, 1910 y 1914), Norwood (1908 y 1954), Nestle (1901, 1941 y 1987), Greenwood (1972) y Murray (1966). 
espacio sagrado es absolutamente claro por la presencia de la divinidad sobre la escena, en la representación enmarcada este espacio se configura de manera paulatina. ${ }^{34}$ Para comprender este proceso, hemos recurrido a la descripción de David Wiles 2003: 24-25, quien describe las distintas maneras en que se configura el espacio sagrado.

Según el autor mencionado, la cultura occidental conoció tres formas básicas del espacio o el lugar divino: en primer lugar, una sección de un páramo, o una piedra o un árbol muy viejo; en segundo lugar, la tumba; la tercera forma es definida por la manera en que el simbolismo interno de alguna conducta se

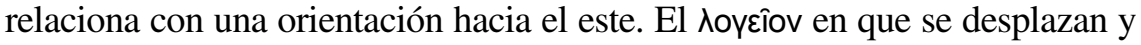
hablan los actores no implica ningún contraste con los otros espacios. Por el contrario, está marcado por la presencia de la tumba de Sémele, muerta por la sorpresiva manifestación del rayo de Zeus, aún humeante al comienzo de la obra; pero, además, las narraciones de los mensajeros, la presencia de Cadmo y de Tiresias travestidos en Bacantes y los milagros del palacio que dejan escapar al profeta del nuevo culto, todo ello alude a un espacio divino que irrumpe dentro del espacio cívico. Incluso, todas las acciones están orientadas en la relación con el profeta y las ménades que llegan desde el este. Nada definitivo, en todo caso, pero siempre se plantea un desafío de interpretación. Todo ello debería llevar a Penteo y a los espectadores en una dirección. Lo exótico, lo ajeno, lo femenino y nocturno, el éxtasis orgiástico, se han hecho presentes sobre Tebas, la ciudad griega. Todos pueden verlo. Todos pueden conmoverse ante la contemplación del contraste entre este emocionalismo ajeno y el racionalismo incomprensivo de Penteo. ${ }^{35}$

Sin embargo, no queremos decir con esto que el poeta hubiera pretendido difundir a través de su obra, al modo de un propagandista religioso, los beneficios de la religiosidad dionisíaca, ${ }^{36}$ ni que intente de alguna manera un camino intermedio que permita alguna conciliación entre racionalismo e irracionalismo. ${ }^{37}$ El último ámbito del espacio escénico terminará de configurar un significado nuevo para la tragedia.

34 Sobre la diferente significación del espacio teatral, cf. McAuley (1999).

35 Sobre racionalismo e impiedad en Eurípides puede consultarse Lefkowitz 1989: 70-82 y 1987: 149-166. También Yunis (1998).

36 Es lo que opinan, entre otros, Gregoire (1961), Jeanmaire (1951), Lesky (1976), Roux (1970 y 1972), Festugiére (1969 y 1972), Lacroix (1976) y Rivier (1944 y 1958).

37 Es lo que han intentado, sobre todo, Dodds (1968), Kauffmann (1978), Jaeger (1985), Kirk (1970), Schmidt (1940), Conacher (1967), Romilly (1971 y 1974), Schaerer (1958), Grube (1941), Oranje (1984), Tovar (1960), Webster (1967) y Winnington-Ingram (1948). 
El punto de partida para el análisis de este espacio de la orchestra está constituido por el canto inicial del coro. Y no se trata solamente del contenido de este canto, tantas veces analizado. ${ }^{38}$ Por el contrario, algo más importante aún que el contenido de este canto lo constituye el significado que las propias mujeres le asignan al espacio de la orchestra.

Las ménades asiáticas han abandonado el Tmolo, en Lidia, para acompañar al profeta que anuncia la nueva religión de Dioniso. En estas circunstancias, y cuando ingresan a Tebas por primera vez, entonan el himno inicial de la tragedia. Cuando este coro de mujeres asiáticas ingresa a escena, su canto representa una clave importantísima para la interpretación y para la comprensión de algunos aspectos del culto dionisíaco del cual surgió el propio teatro. ${ }^{39} \mathrm{El}$ coro de mujeres asiáticas explica lo que constituye el fundamento mítico de sus creencias y, al mismo tiempo, describe el tipo de rituales que practican. ${ }^{40}$ A partir de esta doble explicación por parte del coro de bacantes asiáticas en su primer ingreso a escena, procuramos analizar su canto en una doble referencia: respecto de la consideración de estos rituales como un ejemplo de los mismos cultos que dieron origen al teatro clásico y respecto de la interpretación general de la tragedia como una reflexión sobre el propio quehacer teatral por parte de su autor.

La párodos se divide en un breve preludio (64-72), dos pares de largas estrofas y antiestrofas y un largo epodo. Lo primero que hacen las mujeres en el preludio, antes del comienzo del canto propiamente dicho, es pedir el silencio sagrado previo a la celebración cultual (68-71):

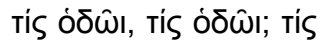
$\mu \varepsilon \lambda \dot{\theta} \theta$ ро

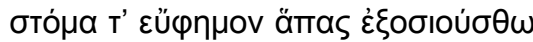

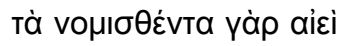

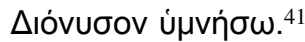

38 Sobre los coros en Eurípides puede verse Parry 1978: 145-225, y sobre la párodos de Bacantes, Festugiere (1972).

39 Cf., entre la copiosa bibliografía, Rodríguez Adrados (1983).

40 Cf. Seaford 1981: 252-275.

41 ¿Quién hay en el camino? ¿Quién hay en el camino? ¿Quién? ¿Que se retire hacia sus moradas, y que toda boca guarde el silencio sagrado! Pues siempre entonaré a Dioniso un himno, cumpliendo con los ritos acostumbrados. 
La orchestra y el teatro mismo (en tanto espacio de la representación escénica, que incluye a los actores y a los espectadores) se convierten de este modo en el lugar donde el ritual no sólo se explica, sino que se ejecuta, se actualiza. Los dos versos finales de esta introducción anuncian lo que veremos y escucharemos a continuación: "Pues siempre entonaré a Dioniso un himno, cumpliendo con los ritos acostumbrados". Es decir, el himno que las mujeres asiáticas nos permitirán escuchar y ver (ya que la indumentaria del culto, así como la danza y la música que acompañan este canto forman una parte inescindible de él) constituye una parte del conjunto de actos que conforman el ritual acostumbrado del culto dionisíaco. El espacio de la representación teatral se ha convertido en espacio de la representación cultual. Los personajes de la representación teatral y los espectadores se convierten, de esta manera, y al mismo tiempo, en testigos y partícipes de una ceremonia de culto. El silencio sagrado pedido por las ménades a los personajes de la tragedia se dirige también a los propios espectadores, que se convierten entonces también en partícipes de la ceremonia cultual. El valor de este aspecto termina de dibujar el significado de los espacios escénicos de Bacantes.

Penteo, a lo largo de la tragedia, ha sido un testigo privilegiado de estas celebraciones. Escucha a las mujeres del coro, dialoga con el profeta de su culto, intenta apresarlo y fracasa, porque los milagros del palacio liberan inmediatamente al profeta, tal como él mismo lo había anticipado. El culto que se representa sobre el escenario, y del cual Penteo y el público son testigos y partícipes, tiene dos aspectos: la calma y la felicidad de las ménades integradas a la naturaleza, la furia destructiva en contra de aquel que se atreve a desafiar las prohibiciones sagradas. La representación de la tragedia es una actualización de este doble aspecto del culto dionisíaco $\mathrm{y}$, al mismo tiempo, una actualización del efecto que la tragedia produce en aquellos que participan de su representación. ${ }^{42}$

Este punto es importante para una reinterpretación de la obra. La tragedia no trata meramente de la difusión de un credo religioso. Eurípides, por el contrario, reflexiona acerca de los efectos de la contemplación de un espectáculo, y con ello, también, acerca de la significación de la tragedia como género artístico. Para cumplir su objetivo, contrasta el resultado que debe esperarse de la contemplación consumada por Penteo, ávido siempre de nuevos espectáculos pero incapaz de comprender su valor sagrado y,

42 Cf. Reynolds-Warnhoff 1997: 77-103. 
por tanto, con una nula reacción ante ellos: ante tanto espectáculo, él no tiene, en realidad, competencia para ver. No hay, como en el caso de la épica, ni compromiso ni efecto catártico por parte del personaje. Penteo ve y sólo quiere ver más, hasta que se atreve a travestirse en una bacante él mismo para poder observar más de cerca a las mujeres en sus cultos. Pero no reacciona ni saca conclusiones. Pasa de un espacio al otro y, peor aún, el propio espacio sagrado lo invade, y él continúa con sus mismas conductas, incapaz de comprender. El mundo entero es un teatro, y el desafío que Eurípides plantea a sus espectadores consiste justamente en este llamado a una reacción diferente de la de Penteo, a una reacción que sea capaz de devolverle a la representación teatral (y, por lo tanto, al propio mundo) la unidad de sentido que, entonces como ahora, parecía entrar en conflicto con estos seres que confían solamente en la fuerza de la razón, pero que son ineptos para comprender la sacralidad del mundo (del teatro) que les toca habitar.

\section{Bibliografía}

Andrés SuÁRez, I. (1997), El teatro dentro del teatro. Cervantes, Lope, Tirso y Calderón. Madrid.

BARrett, J. (1998), "Pentheus and the spectator in Euripides' Bacchae", AJPh 119: $337-60$.

BARTHES, R. ( $\left.{ }^{8} 1994\right)$, “Baudelaire's Theater", in A Barthes Reader. New York, Hill and Wang.

Burns, E. (1972), Theatricality. A Study of Convention in the Theatre and in Social Life. London, Longman.

Buxton, R. (1991), "News from Cithaeron: narrators and narratives in the Bacchae", Pallas 37: 39-48.

Conacher, D. J. (1967), Euripidean Drama: Myth, Theme and Structure. Toronto and London.

Cook, A. J. (1981), The Privileged Playgoers of Shakespeare's London, 1576-1642. Princeton.

Curtius, E. R. (1976), Literatura europea y Edad Media latina, 1. Madrid.

Dabdab Trabulsi, J. A. (1990), Dionysisme, Pouvoir et Société en Grèce jusqu' à la fin de l'époque classique. Paris, Annales Littéraires de l'Université de Besançon. 
De Bouvrie, S. (1997), "Euripides' Bakkhai and Maenadism”, Classica et Mediaevalia 48: 75-114.

DE Jong, I.J.F. (1991), Narrative in drama: the art of the Euripidean messengerspeech. Leiden: Mnemosyne Supp. 116.

DodDs, E. R. (1968), The Bacchae of Euripides. London.

EAsterling, P. E. (1993), “Tragedy and Ritual”, in Scodel, R. (ed.), Theater and Society in the Classical World, Ann Arbor: 7-23.

EAsterling, P. E. (1997), "A show for Dionysus", in Easterling, P. E. (ed.), The Cambridge Companion to Greek Tragedy, Cambridge: 36-53.

Easterling, P. E. (1991), "Euripides in the theatre", Pallas 37: 49-59.

FÉRAL, J. (1985), Théâtralité, écriture et mise en scène. Québec.

Festugière, J. (1969), De l'essence de la tragédie grecque. Paris.

FESTUGiÈRE, J. (1972), "La signification religieuse de la parodos des Bacchantes", "Les mystéres de Dionysos", y "Ce que Tito-Livio nous apprend sur les mystères de Dionysos", in Études de religion grecque et hellenistique. Paris.

FISHER, R. K. (1992), “The 'palace miracles' in Euripides' Bacchae: a reconsideration”, $A J P h$ 113: 179-188.

FOLEY, H. P. (1980), “The masque of Dionysus”, TAPhA 110: 107-133.

FRIEDRICH, R. (1996), "Everything to Do with Dionysus? Ritualism, the Dionysiac, and the Tragic", in Silk, M. S. (ed.), Tragedy and the Tragic. Oxford: 257-283.

García Gual, C. (1975), "Dioniso en la tragedia”, Helmántica 26: 185-198.

GHALI-KaHIL, L. B. (1955), Les enlèvements et le retour d' Hélène dans les textes et les documents figurés. Paris.

Gold, B. K. (1977), “Eủкоб $\mu$ ía in Euripides’ Bacchae”, AJPh 98: 3-15.

Goutman, A. (1992), "Las desventuras de la crítica teatral. Una reflexión sobre la semiología del espectáculo", Memoria del III Encuentro Nacional de Investigación Teatral, México, Instituto Nacional de Bellas Artes: 130-138.

Goward, B. (1999), Telling Tragedy: Narrative Technique in Aeschylus, Sophocles and Euripides. London.

GreEnwood, L. (1972), Aspects of euripidean tragedy. New York.

Gregorre, H. (1961), Euripide. Les Bacchantes, VI, Paris, Les Belles Lettres.

Grube, G. (1941), The Drama of Euripides. London.

Gurr, A. (1992), The Shakespearean Stage 1574-1642. Cambridge.

Hernandez Valcarcel, C. (1988-1989), “Algunos Aspectos del Teatro dentro del Teatro en Lope de Vega”, Anales de Filología Hispánica 4: 75-96. 
IERANÓ, G. (1991), "Forme della necessità nelle Baccanti di Euripide", Dioniso 61: 45-60.

JAEger, W. (1967), Paideia. México.

Jeanmaire, H. (1951), Dionysos. Paris.

KALKE, Ch. (1985), “The making of a Thyrsus: the transformation of Pentheus in Euripides' Bacchae", AJPh 106: 409-426.

Kauffmann, W. (1978, Tragedia y filosofía. Barcelona.

KIRK, S. (1970), The Bacchae of Euripides. Prentice Hall.

Lacroix, M. (1976), Les Bacchantes d' Euripide. Paris.

LefKOwITZ, M. (1987), “Was Euripides an atheist?”, SIFC 3a (ser. V): 149-166.

LefKowitz, M. (1989), “"Impiety” and "atheism” in Euripides' dramas”, CQ 39: $70-82$.

LESKY, A. (1976), Historia de la literatura griega. Madrid.

LuCAS, D. W. (1968), Aristotle Poetics. Oxford.

Matthiessen, A. (1964), “Elektra”, "Taurische Iphigenia” und "Helena”. Untersuchungen zur Chronologie und zur dramatischen Form im Spätwerk des Euripides. Gotinga.

McAuley, G. (1999), Space in Performance: Making Meaning in the Theatre. Ann Arbor.

Montes Huidobro, M. (1982), “Teatro dentro del teatro: técnica preferencial del teatro cubano contemporáneo", in Bustos Tovar, E., Actas del Cuarto Congreso Internacional de Hispanistas, 2: 289-310.

Murray, G. (1966), Eurípides y su tiempo. México (1ra edición inglesa de 1913).

NeSTLÉ, W. (1901), Euripides: Der Dichter der griechischen Aufklärung. Stuttgart.

NeSTLÉ, W. (1941), Von Mythos zum Logos. Die Selbstentfaltung des griechischen Denkens von Homer bis auf die Sophistik und Socrates. Stuttgart.

Nestlé, W. (1987), Historia del espíritu griego. Barcelona.

Norwood, G. (1908), The riddle of the Bacchae. London.

Norwood, G. (1920), Greek Tragedy. Boston.

Norwood, G. (1954), Essays on Euripidean Drama. Berkeley.

Olson, S. D. (1989), “Traditional Forms and Euripidean Adaptation: the Hero Pattern in Bacchae", $C W$ 83. 1: 25-28.

Oranje, H. (1984), Euripides' Bacchae. Ther Play and its Audience. Leiden.

OrOzCO, E. (1969), El teatro y la teatralidad en el Barroco. Barcelona.

PARRY, H. (1978), The lyric poems of Greek tragedy. Toronto-Sarasota. 
Pickard Cambridge, A. (1946), Theatre of Dionysus in Athens. Cambridge.

Pickard Cambridge, A. (1962), Dithyramb, Tragedy and Comedy. Oxford.

Pickard Cambridge, A. (1989), The Dramatic Festivals of Athens. Cambridge.

REYNOLDS-WARnhOFF, P. (1997), "The Role of to sophon in Euripides' Bacchae”, QUCC 57: 77-103.

Rivier, A. (1944), Essai sur le tragique d' Euripide. Lausanne.

RIVIER, A. (1958), "L'élément demonique chez Euripide", in Fondation Hardt pour l' etude de l' antiquité classique, Tome VI, Euripide. Geneve.

Rodríguez Adrados, F. (1983), Fiesta, comedia y tragedia. Madrid.

Romilly, J. (1971), L'évolution du pathétique, d' Eschyle à Euripide. Paris.

Romilly, J. (1974), Le temps dans la tragédie grecque. Paris.

Roux, J. (1970 y 1972), Euripide. Les Bacchantes. Introduction, texte et traduction et Commentaire. Paris.

SAÏD, S. (1989), “L'espace d' Euripide”, Dioniso 59. 2: 107-136.

SCHAERER, A. (1958), L' homme antique et la structure du monde intérieur. Paris.

SCHMIDT, J. (1940), Geschichte der griechischen Literatur. München, I, 3.

SEAFORD, R. (1981), "Dionysiac Drama and the Dionysiac Mysteries", CQ 31: 252-275.

SEAFORD, R. (1987), “Pentheus' Vision: Bacchae 918-22”, CQ 37: 76-78.

SEAFORD, R. (1996), Euripides Bacchae. With Introduction, Translation and Commentary. Warminster-England.

SEEK, G. A. (1985), Unaristotelische Untersuchungen zu Euripides. Heidelberg.

SEgal, Ch. (1982), Dionysiac Poetics and Euripides’ Bacchae. Princeton.

SEGAL, Ch. (1984), “The menace of Dionysus: Sex roles and reversals in Euripides' Bacchae", in Peradotto, J. and Sullivan, J. (Eds.) Women in the ancient World. USA: $195-212$.

Segal, Ch. (1986), Interpreting Greek Tragedy. Myth, Poetry, Text. Ithaca and London.

SEgAL, E. (1991), "Euripides: Poet of Paradox", in Oxford Readings in Greek Tragedy. Oxford: 244-253.

Seidensticker, B. (1979), "Sacrificial ritual in the Bacchae" in Bowersock, G. W. et al. (eds.), Arktouros: Hellenic studies presented to B.M.W. Knox. Berlin: 181-190.

Sousa E SiLVA, M. F. (2005), "Eurípides, crítico teatral”, in Ensaios sobre Eurípides. Lisboa: 243-267. 
Tovar, A. (1960), Eurípides. Tragedias. Las Bacantes- Hécuba, II. Barcelona.

Vernant, J. P y otros (1993), El Hombre griego. Madrid (traducción al español del original L'Uomo greco. Roma-Bari, 1991).

Vernant, J. P. (1985), “Le Dionysos masqué des Bacchantes d'Euripide”, L' Homme 93, 25 (1): 31-58.

Verrall, A. (1910), The Bacchants of Euripides and other essays. London.

Verrall, A. (1914), Euripides, the Rationalist, a study in the history of art and in religion. London.

VILLEGAS, J. (1996), “De la teatralidad como estrategia multidisciplinaria”, Gestos 21: 7-15.

Webster, T. B. L. (1967), The Tragedies of Euripides. London.

Whitehorne, J. (1986), “The Dead as Spectacle in Euripides' Bacchae and Supplices", Hermes 114: 59-72.

WiLes, D. (2003), A Short History of Western Performance Space. Cambridge.

Winkler, J. y Zeitlin, F. (Eds.)(1992), Nothing to do with Dionysos? Athenian Drama in its Social Context. New Jersey.

Winnington-Ingram, R. (1948), Euripides and Dionisus. An interpretation of the Bacchae. Amsterdam.

Yunis, H. (1998), A New Creed: Fundamental Religious Beliefs in the Athenian Polis and Euripidean Drama, Hypomnemata 91: Göttingen.

ZeITLIN, F. (1982), "Cultic models of the female: rites of Dionysus and Demeter", Arethusa 15, 1-2: 129-157.

ZiELINSKI, J. (1927), “De Helenae simulacro”, Eos 30: 54-58. 
